\title{
On the call for issue advocates, or what it takes to make adaptation research useful
}

\author{
Anna Bohman ${ }^{1} \cdot$ Erik Glaas $^{1} \cdot$ Johannes Klein $^{2}$ • \\ Mia Landauer ${ }^{3,4}$ - Tina-Simone Neset ${ }^{1}$. \\ Björn-Ola Linnér ${ }^{1} \cdot$ Sirkku Juhola ${ }^{1,5}$
}

Received: 7 April 2017 / Accepted: 19 June 2018 / Published online: 3 July 2018

(C) The Author(s) 2018

\begin{abstract}
This essay discusses the concept of usefulness of research for climate change adaptation. Based on prior research and stakeholder interactions with policymakers and practitioners in the Nordic countries, we contend that critical issues related to the usefulness of adaptation research seem less associated with content (i.e. research outputs), but rather centre around the efforts made to design and communicate research, that is, to put research at the service of society and make the case for adaptation on the political agenda. This, we argue, to some extent mirrors the situation and political context in the Nordic countries, where adaptation in many locations still is an issue in its infancy, not firmly established on the political agendas, and where working procedures are not yet institutionally settled. In this context, science is considered and sometimes used as a discursive tool to make the case for adaptation. Based on the calls for research that inspires, raises hope and helps to raise the issue of adaptation on the political agendas, we elaborate the role of honest issue advocates for researchers in the field of adaptation science.
\end{abstract}

Anna Bohman anna.bohman@liu.se

1 Department of Thematic Studies - Environmental Change, Centre for Climate Science and Policy Research, Linköping University, Linköping, Sweden

2 Geological Survey of Finland, Espoo, Finland

3 Arctic Centre, University of Lapland, Rovaniemi, Finland

4 International Institute for Applied Systems Analysis (IIASA), Laxenburg, Austria

5 University of Helsinki \& Helsinki Institute of Sustainability Science(HELSUS), Helsinki, Finland 


\section{Introduction-the "what" and "how" of useful adaptation research}

Research on and for climate change adaptation has increased significantly in the past decade. ${ }^{1}$ Conceptual and empirical work has aimed to identify, e.g. barriers and facilitating factors for implementation (Eisenack et al. 2014; Biesbroek et al. 2013; Moser and Ekstrom 2010), the consequences of adaptation policy (Sovacool and Linnér 2016), and how adaptation planning evolves in different contexts (Klein 2016; Klein et al. 2016; Juhola et al. 2014).

As a lack of knowledge for adaptation has been identified as a bottleneck to implementation, European governments are continuously investing in this area (Moser and Boykoff 2013; Commission on Climate and Vulnerability 2007). The expectation is that by filling identified knowledge gaps, actions leading towards a robust and climate-resilient society will follow. In the same vein, there is a growing demand on science to inform adaptation decisions (Eakin and Patt 2011; NRC 2009) and a turn towards the need for "climate services" (van den Hurk et al. 2016; Kirchhoff et al. 2013). This is in line with more general trends within the science-policy field, where the last three decades have seen calls for a "new" role of science, attuned to the knowledge needs of various societal groups (e.g. Jasanoff 2004; Nowotny 2003; Gibbons 1999; Gibbons et al. 1994).

Correspondingly, a debate has emerged on the need for research that puts scientific results at the service of society (i.e. science for adaptation), as opposed to a more theoretical focus (i.e. science on adaptation) (Swart et al. 2014). The former has been described as research produced in the context of application with an explicit aim to provide knowledge that is useful for identifying specific adaptation actions and for guiding implementation (Preston et al. 2015).

Critics, however, argue that investments in adaptation research are being made without well-grounded knowledge on "how science can or should contribute to successful adaptation" (Moser and Boykoff 2013; Preston et al. 2015), especially since no large-scale or systematic studies on the effectiveness of adaptation research have been published yet. The probing question therefore is how we can make adaptation research "knowable" and "actionable" (Moser and Boykoff 2013; Kalafatis et al. 2015); that is, what kind of research is perceived as useful to facilitate successful adaptation on the ground?

With this essay, we contribute to this debate by analyzing how usefulness in adaptation research is perceived and discussed by targeted stakeholders in the Nordic countries and the associated implications for the role of research and researchers. As an input to the analysis, we draw on experiences from stakeholder interactions in the NORD-STAR project more generally, and especially on the outcomes from a final project workshop held with adaptation practitioners from the five Nordic countries. The Nordic research program on strategic adaptation research (NORD-STAR) ran between 2011 and 2016 and included a large number of participatory stakeholder studies. The workshop described below was part of the NORD-STAR project and aimed to discuss what useful adaptation research means and what can be done to make it happen. Besides recordings and transcripts from the workshop, as well as discussions with stakeholders, we also draw more generally on experiences from previous and ongoing research projects, as well as consultancies and

\footnotetext{
${ }^{1}$ For this paper, a broad definition of applied adaptation research is used; it is defined as research that produces information that is used, or is intended for use, by adaptation practitioners to cope with climate variability and change. It thereby includes both social sciences, as well as research meant to advance the general knowledge base on climate change and the physical science basis.
} 
science-policy interaction within this field. This has provided a broader and deeper understanding of issues discussed in this paper. ${ }^{2}$

\section{Workshop set-up}

The workshop was held as a whole day event in the Norrköping Decision Arena, ${ }^{3}$ Sweden, in November 2015. It involved eight participants from environment- and climate-related agencies and authorities, as well as municipalities and county boards from all five Nordic countries (Appendix Table 1). We refer to the participants as adaptation practitioners, which means they are professionals in different organizations set to manage, plan and effectuate climate adaptation measures and policies. In the first part of the workshop, participants were asked to present examples of how they use adaptation research findings in their professional activities. The discussion that followed focused on what made this research useful or not to their daily practice. A second exercise more specifically targeted future research demands, where participants were asked to jot down their ideas about what kind of research they would like to see in the future; these were later gathered as post-it notes, sorted into categories and presented in plenum. The final session discussed specific demands for making research useful. Participants were asked to brainstorm around this issue in smaller break-out groups, synthesize ideas and create a shortlist of how to translate research into practice.

\section{Views on useful adaptation research}

When discussing the "usefulness" of adaptation research, participants spontaneously raised topics that largely centred upon the wide-ranging theme of knowledge brokering, i.e. to make research more accessible to different audiences. Issues more specifically discussed here were how to enable uptake and impact of research through presentation formats, the research design process, and the discursive framing of climate adaptation itself, that is, how adaptation is talked and written about and how that affects the general implementation context and political priority.

Generally, participants agreed that visual formats are essential for successful communication, as it makes people interested and thus spurs engagement in adaptation issues beyond the traditional adaptation community, i.e. those that are already committed and work actively with the issue. These statements are in line with previous studies on climate communication (Ballantyne et al. 2017) and the development of interactive tools (Glaas et al. 2017; Neset et al. 2016; Bohman et al. 2015), which stress the importance of clear visual outputs for awareness raising and for creating engagement and involvement. In this context, maps as a medium for presenting information (related to practical implementation) were discussed in more detail. Participants argued that, while maps are great at giving an overview of information

\footnotetext{
${ }^{2}$ Although the workshop provides the primary reference for the argument presented here, other projects and experiences have largely contributed to our understanding of these issues. This includes stakeholder interactions held in other sub-studies within the NORD-STAR project, such as interviews with municipal officials in Trondheim to discuss adaptation and integrated vulnerability using the visualization tools VisAdapt ${ }^{\mathrm{TM}}$ and ViewExposed $^{\mathrm{TM}}$ (Bohman et al. 2015), and with homeowners in Aarhus, Denmark, Norrköping, Sweden and Trondheim, Norway, to discuss climate risks and adaptation alternatives using the VisAdapt ${ }^{\mathrm{TM}}$ tool (Glaas et al. 2017; Neset et al. 2016). Moreover, interviews have been held with municipal officials in Swedish cities to discuss co-production of climate vulnerability assessments (Glaas and Jonsson 2014), and adaptation measures in the cities of Copenhagen and Helsinki (Klein et al. 2017).

${ }^{3} \mathrm{https}$ ///iu.se/en/research/the-norrkoping-decision-arena
} 
with a spatial dimension, they are not always "actionable", if the user lacks the adequate background in terms of competencies and skills, as exemplified in the following quote:

Maps are great but sometimes expertise is needed to interpret the maps, a guide on how to use the map...what does it show, what decisions can I make when it looks like that? And what is the next step? ? $^{4}$

This statement confirms that some administrations consider themselves to lack experience and knowledge on how to move from visual representations of climate data and impacts to identification of possible response measures (Bohman et al. 2015; Klein and Juhola 2014). This also reflects that societal actors are just beginning to learn how to tackle impacts of climate change. Moreover, climate adaptation puts new demands on policymakers and practitioners in that they are expected to master many different problem areas and be trained both as generalists and specialists. These changing circumstances might also be a reason for new demands on researchers to be deeply involved in local and national adaptation processes, and to provide expert advice along the way.

Participants at the workshop stressed that research results need to be presented in a way that ensure their relevance for ongoing processes and contextual differences. To enable an uptake of findings, researchers need to have a clear picture of who is likely to use the knowledge they produce, and where in the adaptation process these users would situate themselves. As our results indicate, this is especially challenging in a context where local governments have strong autonomy over local decisions, as is the case in the Nordic countries (Klein et al. 2016) and where research outcomes often need to be interpreted at the local level with limited assistance from the national government in terms of competences or resources (Juhola et al. 2014; Goodsite et al. 2013).

In terms of research design, the workshop participants stressed that participatory research provide opportunities to co-produce knowledge, while simultaneously providing channels for dissemination of the results. This kind of research design would respond to the dual challenge of knowledge production, where research users get a chance to participate in the identification of a research agenda, while also getting immediate access to research results (c.f. Glaas and Jonsson 2014; Wamsler 2017). Such co-production of knowledge typically spurs implementation by the very way research is carried out. Therefore, besides involving users in project planning and reference groups, participants further strongly argued for the need to involve end-users in communicating research results. They argued that research projects should acknowledge that although climate adaptation may be a relatively well-defined research field, it is rarely an isolated issue for planners, who think in terms of adaptation measures in the wider context of planning. This has also been underlined by Klein amd Juhola (2014) and others who argue that researchers in the field rarely recognize that adaptation is not the main priority for many stakeholders. To illustrate: a physical measure such as a park or a green space for storm water drainage typically serves more than one purpose (multi-functionality), and for those engaged in on-the-ground realities of, i.e. municipal spatial planning, adaptation is only one of several issues that must be taken into consideration. This is a reality that should be reflected in the way that research is carried out. Thus, besides putting research consortia together in a way that reflect the multi-dimensional nature of climate adaptation, scholars were urged to step out of the climate community and find methods for bringing stakeholders from different fields together.

Moreover, positive narratives were brought up as a way to reach out to policymakers and planners, and to make research results more attractive. Researchers were urged to target solutions rather than problems and "to move into a visualization of a more positive future". 5 Stakeholders

\footnotetext{
${ }^{4}$ Climate adaptation Coordinator, Swedish County Board.

${ }^{5}$ Representative from the Danish Centre for Environment and Energy, Denmark.
} 
further call for researchers to more actively highlight added values and benefits of adaptation actions, point to solutions, inspire, and raise hope. This demand for a more positive framing indicates that research on adaptation so far has been caught up in a discourse of failure, where adaptation first and foremost is talked about as a response to failed mitigation action. As one participant put it:

Avoided damage doesn't really turn people on. Opportunities do, something that they gain. ${ }^{6}$

This would imply that project design and research questions should apply a more positive (or constructive) narrative, move away from solely focusing on risk reduction, address solutions rather than problems and thereby inspire people to act.

Stakeholders also argued that knowledge brokering must be more meritorious than it is today and should be considered as an important part of the academic curricula. The research task should not be considered completed once an article is published in an academic journal; researchers must also be skilled in reaching out and marketing their results. Presently, responsibilities for research communication were perceived as somewhat blurred, why a clarification regarding roles and responsibilities was requested. In addition, for knowledge brokering to be improved, it must come with additional resources. A few new research calls and initiatives in the Nordic region indicate that such a change may be under way. ${ }^{7}$

In terms of future research needs, the most common requirement brought up by stakeholders was different methods for cost-benefit analysis. As much as this can be classified as an instrument for decision support, it is also a tool for public officials to communicate with politicians, with the assumption that talking in money terms will make things happen. Again, this relates to the need to "make the case for adaptation" on the political agenda.

To conclude, the topics raised in the discussions among Nordic stakeholders indicate that the most critical issues regarding the usefulness of adaptation research are not primarily related to content (in terms of increasing the stock of knowledge by addressing critical knowledge gaps),but are first and foremost about how research results are packaged and communicated. Stakeholders called for researchers both to furthering efforts to adjust and present research results to make them feed into ongoing processes but also for a more active role of the researcher as agenda setter.

The above does not automatically imply that researchers uncritically should provide practitioners with what they request or say what they want to hear. However, if we are serious about our ambitions in producing actionable and knowable research, then the above should be treated as valuable insight into the thinking and acting of those actively involved in realizing adaptation on the ground. In the following, we consider this as food-for-thought in the further discussion on the dynamics of science-policy interactions within this field.

\section{What role for research(ers) in adaptation policy and practice?}

There is a sense within the adaptation community that we need to move beyond the statement that "more knowledge" is needed. Certainly, considerable knowledge gaps persist and there are many unidentified parameters relevant to the field of climate adaptation. Still, themes

\footnotetext{
${ }^{6}$ Representative from the Danish Centre for Environment and Energy, Denmark

${ }^{7}$ One of them is the recent Swedish call "Viable Cities" funding for research and action intended to work as a "catalyst for new forms of cooperation between cities, business, academia, research institutes and civil society to develop and utilize innovation and knowledge for smart sustainable cities" (http://viablecities.com). Another example is provided by the Strategic Research Initiative in Finland http://www.aka.fi/en/strategic-research-funding/
} 
brought up at the workshop discussions confirm observations from previous and ongoing stakeholder interactions: the most critical issues for useful Nordic adaptation research relate to form rather than content. Importantly, these do not exclude one another, that is, we certainly do not argue that research should not aim at addressing knowledge gaps/information deficits, but unless we also turn our attention to and put more effort into developing the design, the presentation format and dialogue of research, neither existing nor future research will be adequately put to use. The importance of contextualizing and adapting the design and outputs of climate-related research to the decision-making contexts it is intended to inform, has been similarly stressed in previous research (e.g. Feldman and Ingram 2009).

In line with this, useful research was at the workshop not primarily discussed and defined as research that generates new data or increases the stock of knowledge by addressing critical information gaps, but rather research that is packaged and communicated in a way that makes the findings "knowable", actionable" (Moser and Boykoff 2013) makes things happen and hence acts as a catalyst for change.

In the same vein, scholars were urged by the stakeholders to be more actively involved in promoting and increasing the attractiveness of the issue of climate adaptation by showcasing solutions, inspiring and raising hope, i.e. moving from a problem oriented to a solutionoriented framing. In other words, researchers were not only called for in their role as knowledge producers but as agenda setters where science is used as a "discursive tool" (Moser and Boykoff 2013) to build political support for adaptation.

We interpret this request as a call for issues advocates ${ }^{8}$ (Pielke 2007), who use positive framing to set off action and market research results in a more proactive way. Advocacy in this context, however, was called for by stakeholders to raise and establish the issue on the political and media agendas rather than actively promoting certain action alternatives (which in this case could be adaptation measures) over others at the implementation stage.

This, we argue, to some extent reflects the situation and political context in the Nordic countries, where adaptation in many locations still is an issue in its infancy, not firmly established on the political agendas, and where working procedures are not yet institutionally settled. In this context, science is considered and sometimes used as a "discursive tool" (Moser and Boykoff 2013) to gain political support for adaptation and in this way creating enabling opportunities for proceeding with adaptive action.

So, to what extent and with what consequences would researchers be ready to play the role of "issue advocates" to meet the needs of policymakers and planners working on climate adaptation? This question inevitably touches upon the longstanding debate on the politics of science. Here, two polarized positions can be found in the discussion, where traditional scholars would argue that science should not prescribe policy and that "a clear distinction

\footnotetext{
${ }^{8}$ Without specific reference to climate change adaptation, Pielke Jr. (2007) depicts four stereotype roles for researchers that highlights different approaches as for how to act in the context of policy and politics. He separates between:

1. the Pure Scientist who conduct research without any consideration on the use of the research outcomes in society,

2. the Issue Advocate who explicitly considers the implication of the research outcomes for a specific political agenda and make the case for one policy option over others.

3. the Science Arbiter who wish to stay removed from policy, but still focus on issues which are highly relevant in contemporary policy, and

4. the Honest Broker who tries to produce research outcomes which open up a smorgasbord of policy options without promoting one specific option or policy.
} 
needs to be drawn between the presentation of evidence and advocacy of policy responses" (Morecroft et al. 2014: 842). The underlying idea being that there is no room for politics in science; that researchers should act as and be looked upon as purely information resources and avoid explicit engagement of policy alternatives. The other strand would argue for the importance of recognizing that science cannot be isolated from societal power structures but inevitably is part of the battle between political interests. The latter, in our example, could imply that researchers act as agenda setters or issue advocates by, e.g. raising awareness and enhancing visibility of perspectives, which so far have been somewhat overshadowed by prevailing narratives.

Looking at the history of environmental science, researchers have mainly drawn attention to new environmental problem areas by drawing on warnings and worst-case scenarios and outlining what may happen if an issue is not addressed (cf. Hjerpe and Linnér 2009). The stakeholders in this study emphasize the importance of positive framing to spur action by pointing at positive effects and added benefits that are generated by addressing climate adaptation. This is in line with the climate change communication literature, which emphasizes "the importance of positive feedback on individual actions, locally and personally relevant framings of climate change, visibility and concretization of climate change-related issues and a focus on solutions rather than on catastrophic consequences of climate change" (Wibeck 2014:402). The question emerges as to why researchers would be less inclined to be "positively framing issue advocates" in the realm of adaptation policies?

We argue that adaptation research is still largely caught up in a discourse of failure, in which avoiding risk is the paramount goal of adaptation policy and implementation. In contrast, the Paris Agreement highlights the wider benefits of adaptive action. The Parties agreed on an adaptation goal of "enhancing adaptive capacity, strengthening resilience and reducing vulnerability to climate change, with a view to contributing to sustainable development..." (UNFCCC 2015, Art 7). By linking adaptation to broader sustainability issues and opportunities to build an attractive and resilient future, researchers could more explicitly highlight opportunities to be seized for taking action. In the same vein, research for adaptation could be more proactive in trying to demonstrate the added values and benefits of different options in the context of application. This certainly does not imply that scientist should always actively frame information to paint rosy pictures of positive futures. Neither does it mean that we opt for science where researchers give up the pursuit of independence and objectivity, nor should drawbacks of policies and measures be deemphasized.

However, if researchers find that prevailing narratives have been biased, then the role of researchers should be to raise awareness and contribute to pluralistic narratives by emphasizing alternative framings. An important role of researchers could then be to demonstrate and highlight that there are other ways of telling a story, by acknowledging and recognizing that there is always a discourse in which politics, policy and action programs are situated.

In Pielke Jr.'s (2007) terminology, this could imply assuming a role between an honest broker and issue advocate, what we refer to as an "honest issue advocate", not with the aim of "strictly reducing choice" but rather to be honest about the explicit aim of raising the issue of climate adaptation on the political agenda and thereby avoid slipping into "stealth issue advocacy". Moreover, the honest issue advocate seeks to make research accessible and tangible by reducing the "background noise" in the massive information flow and actively 
target various users and contextualize results in ongoing policy and planning. Drawing on the discussions above this would demand researchers to:

- Strive to gain a better understanding of the processes wherein the knowledge is meant to be put to use

- Be clear about the specific processes and audiences targeted, and where in the process outcomes can feed in

- Involve end-users in the research process and as reference group

- Work more proactively with the visual format and interactive exploration of outcomes

- Be more proactive in showcasing added values and benefits of different adaptive options

- Link adaptation to broader sustainability issues and to societal transformations

Paying attention to these points, we argue, could contribute to enable the uptake of research findings among practitioners and thereby support implementation.

\section{Appendix}

Table 1 List of actors/institutions represented at the workshop in Norrköping, Sweden

- Danish Centre for Environment and Energy, Denmark

- Helsinki Environmental Regional Services Authority, Finland

- Ministry of Agriculture and Forestry, Finland

- Department of Environment and Planning, Reykjavik City, Iceland

- Climate and Energy Group, Trondheim municipality, Norway

- Norwegian Ministry of the Environment, Norway

- National Knowledge Centre for Climate Adaptation, Swedish Meteorological and Hydrological Institute, Sweden - Regional County Board, Stockholm, Sweden

Open Access This article is distributed under the terms of the Creative Commons Attribution 4.0 International License (http://creativecommons.org/licenses/by/4.0/), which permits unrestricted use, distribution, and reproduction in any medium, provided you give appropriate credit to the original author(s) and the source, provide a link to the Creative Commons license, and indicate if changes were made.

\section{References}

Ballantyne A.G., Glaas E., Neset T-S and Wibeck V. (2017) Localizing climate change: Nordic homeowners' interpretations of visual representations for climate adaptation. Environmental Communication 12(5):638652. https://doi.org/10.1080/17524032.2017.1412997

Biesbroek GR, Klostermann JEM, Termeer CJAM, Kabat P (2013) On the nature of barriers to climate change adaptation. Reg Environ Chang 13(5):1119-1129

Bohman A, Neset T-S, Opach T, Rød JK (2015) Decision support for adaptive action: assessing the potential of geographic visualization. J Environ Plan Manag 58(12):2193-2211

Commission on Climate and Vulnerability (2007) Sweden facing climate change - threats and opportunities. Swedish Govern Off Rep SOU 2007:60 679 pp

Eakin CE, Patt A (2011) Are adaptation studies effective, and what can enhance their practical impact? WIREs Climate Change 2(2):141-153

Eisenack K, Moser SC, Hoffmann E, Klein RJT, Oberlack C, Pechan A, Rotter M, Termeer CJAM (2014) Explaining and overcoming barriers to climate change adaptation. Nat Clim Chang 4(10):867-872 
Feldman DL, Ingram HM (2009) Making science useful to decision makers: climate forecasts, water management, and knowledge networks. Weather, Climate, Society 1:9-21

Gibbons M (1999) Science's new social contract with society. Nature 402:C81-C84

Gibbons M, Limoges C, Nowotny H, Schwartzman S, Scott P, Trow M (1994) The new production of knowledge: dynamics of science and research in contemporary societies. Sage, Thousand Oaks

Glaas E, Jonsson A (2014) Facilitating cross-sectoral assessments of local climate change vulnerability. Int J Urban Sustain Dev 6(2):174-189

Glaas E, Ballantyne AG, Neset T-S, Linnér B-O (2017) Visualization for supporting individual climate change adaptation planning: assessment of a web-based tool. Landsc Urban Plan 158:1-11

Goodsite ME, Davis M, Klein R, Davidsdottir B, Atlason RS, Juhola S, Landauer M, Linnér, B-O, Neset TS, Glaas E, Eskeland G (2013) White paper: climate change adaptation in the Nordic countries. Nordic climate, mitigation, adaptation and economic policies network (N-CMAEP), Norden Top-Level Research Initiative, Oslo, Norway

Hjerpe M, Linnér B-O (2009) Utopian and dystopian thought in climate change science and policy. Futures 41(4):234-245

Jasanoff S (2004) States of knowledge. The co-production of science and social order. Routledge, London

Juhola S, Goodsite ME, Davis M, Klein RJT, Davıdsdottir B, Atlason R, Landauer M, Linnér B-O, Neset T-S, Glaas E, Eskeland G, Gammelgaard Ballantyne A (2014) Adaptation decision-making in the Nordic countries: assessing the potential for joint action. Environ Syst Decis 34(4):600-611

Kalafatis SE, Lemos MC, Lo YJ, Frank KA (2015) Increasing information usability for climate adaptation: the role of knowledge networks and communities of practice. Glob Environ Chang 32:30-39

Kirchhoff CJ, Carmen Lemos M, Dessai S (2013) Actionable knowledge for environmental decision making: broadening the usability of climate science. Annu Rev Environ Resour 38:393-414

Klein J (2016) Embeddedness of climate change adaptation: established procedures and contending discourses for flood protection in Espoo, Finland. Local Environ 22(2):254-271

Klein R, Juhola S (2014) A framework for Nordic actor oriented adaptation research. Environ Sci Pol 40:101-115

Klein J, Mäntysalo R, Juhola S (2016) Legitimacy of urban climate change adaptation: a case in Helsinki. Reg Environ Chang 16(3):815-826

Klein J, Juhola S, Landauer M (2017) Local authorities and the engagement of private actors in climate change adaptation. Environ Plan C 35(6):1055-1074

Morecroft MD, Crick HQP, Duffield SJ, Macgregor NA, Taylor S (2014) Correspondence: enhancing the impact of climate science. Nat Clim Chang 4(10):842-843

Moser SC, Boykoff MT (2013) Successful adaptation to climate change_-linking science and policy in a rapidly changing world. Routledge, New York

Moser SC, Ekstrom JA (2010) A framework to diagnose barriers to climate change adaptation. PNAS 107(51): 22026-22031

Neset T-S, Glaas E, Ballantyne AG, Linnér B-O, Opach T, Navarra C, Johansson J, Bohman A, Rød JK, Goodsite M (2016) Climate change effects at your doorstep: geographic visualization to support Nordic homeowners in adapting to climate change. Appl Geogr 74:65-72

Nowotny H (2003) Democratising expertise and socially robust knowledge. Sci Public Policy 30(3):151-156

NRC (National Research Council) (2009) Informing decisions in a changing climate. In: Corell R, Lee K (eds) Committee on the human dimensions of global change. National Academic Press, Washington, DC

Pielke RA Jr (2007) The honest broker: making sense of science in policy and politics. Cambridge University Press, Cambridge

Preston BL, Rickards L, Fünfgeld H, Keenan RJ (2015) Toward reflexive climate adaptation research. Curr Opin Environ Sustain 14:127-135

Sovacool BK and Linnér B-O (2016) The political economy of climate change Adaptation, Palgrave McMillan., Basingstoke UK

Swart R, Biesbroek R, Lourenço TC (2014) Science of adaptation to climate change and science for adaptation. Front Environ Sci 2:29

UNFCCC. (2015) Paris Agreement, Conference of the Parties on its twenty-first session. https://doi. org/FCCC/CP/2015/L.9/Rev.1

van den Hurk BJ, Bouwer LM, Buontempo C, Döscher R, Ercin E, Hananel C, ..., Pappenberger F (2016) Improving predictions and management of hydrological extremes through climate services: www.imprex.eu. CLISER 1:6-11

Wamsler C (2017) Stakeholder involvement in strategic adaptation planning: Transdisciplinarity and coproduction at stake? Environ Sci Pol 75:148-157

Wibeck V (2014) Enhancing learning, communication and public engagement about climate change: some lessons from recent literature. Environ Educ Res 20(3):387-411 